\title{
PRÁTICA EXTENSIONISTA NO TERCEIRO SETOR: CAPACITAÇÃO PARA A COMUNICAÇÃO NA MÍDIA SOCIAL DIGITAL FACEBOOK
}

\author{
Kássia Nadine Lutz \\ Universidade Federal de Santa Maria \\ kassialutz@gmail.com \\ Jones Machado \\ Universidade Federal de Santa Maria \\ jonesm2@outlook.com
}

\begin{abstract}
Resumo
O projeto de extensão "Formação de Multiplicadores em Mídias Digitais para Organizações do Terceiro Setor" foi desenvolvido no ano de 2017, em Frederico Westphalen (RS), na Apae, Cufa e Feira do Produtor. Sabendo que a midiatização modifica as relações sociais, principalmente no ambiente digital, o objetivo do projeto foi capacitar gestores e voluntários de ONGs para uma atuação planejada em mídias digitais, contribuindo para a comunicação organizacional e para a missão das entidades. Diante disso e levando em conta as premissas da extensão universitária e das Relações Públicas no Terceiro Setor, realizou-se entrevista aberta com os gestores das organizações e observação não-participante de suas fanpages para o diagnóstico da comunicação digital. Em seguida, foi planejado o conteúdo das oficinas, elaborado o material didático e a cartilha de presença e atuação em mídias digitais. Após o desenvolvimento das ações, percebeu-se que foi apenas o começo da "formação de multiplicadores", pois o nível de conhecimento sobre mídias digitais nas entidades ainda é básico.
\end{abstract}

Palavras-chave: Extensão. Terceiro Setor. Mídias Digitais. Facebook. Relações Públicas.

\section{EXTENSIONIST PRACTICE IN THE THIRD SECTOR: CAPACITATION FOR COMMUNICATION IN THE DIGITAL SOCIAL MEDIA FACEBOOK}

\begin{abstract}
The extension project entitled "Multiplier Training in Digital Media for Third Sector Organizations" was developed during the year 2017 in the city of Frederico Westphalen, RS, with "Apae", "Cufa" and "Feira do Produtor". Knowing that mediatization has changed the form of social relations especially in the digital environment the objective of the project was to train managers and volunteers of organizations of Third Sector for a planned performance in digital media, contributing for organizational communication and entities' mission. Faced with this and taking into account the premises of university extension and Public Relations in the Third Sector an open interview was conducted with the managers of attended organizations and non-participant observation of their fanpages for the diagnosis of digital organizational communication. Then it was possible planning the content of given workshops and elaborating the didactic material and the hornbook of presence and performance in digital media. After developmenting actions, it was noticed that they were only a beginning for this "formation of multipliers", because the knowledge level about digital media in these entities is still basic.

Keywords: Extension. Third Sector. Digital Media. Facebook. Public Relations.
\end{abstract}

\section{PRÁCTICA EXTENSIONISTA EN EL TERCERO SECTOR: CAPACITACIÓN PARA LA COMUNICACIÓN EN LO MEDIO SOCIAL DIGITAL FACEBOOK}

\begin{abstract}
Resumen
El proyecto de extensión titulado "Formación de Multiplicadores en Medios Digitales para Organizaciones del Tercer Sector" fue desarrollado durante el año 2017 en la ciudad de Frederico Westphalen, RS, com "Apae", "Cufa" y "Feita do Produtor". Sabiendo que la mediatización modificó la forma de las relaciones sociales, principalmente en el ambiente digital, el objetivo del proyecto fue capacitar a gestores y voluntarios de organizaciones del Tercer Sector para una actuación planificada en medios digitales, contribuyendo con la comunicación organizacional y la misión de las entidades. Ante ello y teniendo en cuenta las premisas de la extensión universitaria y de las Relaciones Públicas en el Tercer Sector, se realizó una entrevista abierta con los gestores de las organizaciones atendidas y observación no participante de sus fanpages para el diagnóstico de la comunicación organizacional digital. Em seguida, fue posible planificar el contenido de los talleres impartidos y elaborar el material didáctico y la cartilla de presencia y actuación en medios digitales. Después del desarrollo de las acciones, se percibió que ellas fueron apenas un comienzo para la "formación de multiplicadores", pues el nivel de conocimiento sobre medios digitales en esas entidades sigue siendo básico.

Palavras clave: Extensión. Tercer Sector. Medios Digitales. Facebook. Relaciones Públicas.
\end{abstract}


Prática extensionista no terceiro setor: capacitação para a comunicação na mídia social digital Facebook

\section{INTRODUÇÃO}

A compreensão das mudanças na cultura e na sociedade passa pelo fenômeno da midiatização no qual, segundo a Teoria da Midiatização defendida por Hjarvard (2014), há uma articulação permanente e profunda entre a mídia e a vida cotidiana, por meio de um conjunto de fenômenos que alteram a lógica de funcionamento das práticas humanas, organizacionais e institucionais, além de contribuírem para a formação da opinião pública. Tais mudanças propiciaram aos cidadãos a possibilidade de experimentar a interação mútua, o contato com outros a quilômetros de distância, a oportunidade de aprender sem sair de casa, a expressão de suas ideias ativamente, a contribuição com outras pessoas/causas em tempo real, entre tantas outras potencialidades que a tecnologia digital trouxe.

Nesse contexto de midiatização, não apenas cidadãos e a mídia buscam dar visibilidade (THOMPSON, 1998) às suas pautas, mas também as organizações, seja por intermédio dos media ou de blogs e outras mídias sociais digitais, como Facebook e Instagram, que podem cada vez mais alcançar um maior número de pessoas em menor tempo. Por isso, a comunicação das organizações públicas, privadas e do Terceiro Setor precisa estar preparada para acompanhar as transformações do cenário midiático, uma vez que com a internet a comunicação organizacional foi energizada. Assim, cada vez mais, faz-se necessário planejar a comunicação de forma estratégica, levando em conta as características específicas que a internet traz, a exemplo da exigência de interação e do aumento da transparência, ambas cada vez mais reivindicadas pela sociedade.

Nessa linha, ancorado principalmente em Pérez (2001, 2012), entende-se por estratégia de comunicação um conjunto planejado e contínuo de ações de comunicação originadas em processos de pensamento, que consideram o entorno (pessoas, organizações, políticas e processos) e levam à tomada de decisões que buscam o alcance das metas e dos objetivos organizacionais de forma relacional. Nesse sentido, a comunicação pensada de forma estratégica se mostra essencial em todos os tipos de instituições, uma vez que se torna um importante auxílio para alcançar os objetivos organizacionais, podendo ser ainda mais potencializada pelas mídias sociais digitais, se realizada da forma correta.

Por isso mesmo, destaca-se a importância de uma comunicação digital estratégica também nas organizações do terceiro setor, que se denominam não-governamentais, de direito privado e sem fins lucrativos, já que atendem aos propósitos públicos que muitas vezes o Estado não é capaz de prover com totalidade ou qualidade, como saúde, segurança, educação. Lima (2004) acrescenta que as entidades do terceiro setor contribuem para a construção de uma sociedade 
Prática extensionista no terceiro setor: capacitação para a comunicação na mídia social digital Facebook

menos centrada em questões individuais e mais voltada para os direitos de grupos. Esforços nesse sentido contribuem para o entendimento de que todos os cidadãos possuem responsabilidade sobre o espaço público, desenvolvendo também o conceito de cidadania.

Entretanto, fatores apontados por Silva, Guedes e Santos (2017) como a desigualdade social, a corrupção no sistema político e a busca apressada pelo sustento diário que acaba por esgotar física e psicologicamente o cidadão, muitas vezes, dificultam a participação e o engajamento das pessoas em causas sociais. Por isso, no cenário de midiatização apresentado, as entidades do terceiro setor podem se utilizar de estratégias de comunicação digital para atender seus principais objetivos, como maior aproximação com a comunidade, estabelecimento de parcerias e captação de doações. Além disso, a visibilidade propiciada no ambiente digital pode contribuir também para a prospecção de voluntários que possam colaborar com as causas da entidade, seja com capital financeiro ou humano.

Tendo em vista todas estas questões, identificou-se na prática extensionista a possibilidade de auxiliar na adaptação e qualificação das organizações do Terceiro Setor de Frederico Westphalen ao processo de comunicação digital estabelecido por meio de planejamento, interação e estratégia. Surgiu assim o projeto de extensão intitulado "Formação de Multiplicadores em Mídias Digitais para Organizações do Terceiro Setor” (Multiplicador3S), ligado à Universidade Federal de Santa Maria campus Frederico Westphalen (UFSM-FW). Com isso, o objetivo do "Multiplicador3S" consistiu em capacitar gestores e voluntários de organizações do Terceiro Setor para uma atuação planejada e estratégica em mídias digitais, a fim de dar visibilidade às ações desenvolvidas pelas entidades envolvidas, gerar proximidade com a comunidade, captar apoio, doações e voluntários, qualificando a comunicação organizacional e contribuindo para a missão das entidades.

Para atender ao objetivo geral, foram previstos os seguintes objetivos específicos: a) realizar diagnóstico de comunicação junto aos coordenadores das organizações; b) desenvolver oficinas sobre presença digital para gestores e voluntários das organizações; c) elaborar material didático instrutivo para subsídio às oficinas; d) desenvolver cartilha que oriente as organizações na ambiência da internet; e e) avaliar o nível estratégico da presença e da atuação digital das organizações antes e depois da execução do projeto.

Como o "Multiplicador3S" se viabilizou por meio da extensão universitária, foi necessário levar em conta as premissas básicas deste pilar da Universidade. Com base na Política Nacional de Extensão Universitária (2012), concebe-se a extensão universitária como uma troca de saberes acadêmicos e populares que, por sua vez, irão resultar na democratização do conhecimento e a criação de um vínculo entre a comunidade e universidade. Frente a isso, é pertinente citar a ideia 
Prática extensionista no terceiro setor: capacitação para a comunicação na mídia social digital Facebook

de Freire (1979) de que a extensão e educação devem estar pautadas em uma interação dialógica, ou seja, no diálogo e interlocução de sujeitos, com o objetivo de compartilhamentos de significados e compreensão mútua, e não na mera transferência dos saberes e técnicas por parte do educador.

Aliada a essa ação de diálogo para entender a necessidade das entidades, considerou-se também a atuação de Relações Públicas no Terceiro Setor (LIMA, 2004; PERUZZO, 2007), principalmente no que tange à realização do diagnóstico da comunicação organizacional, no qual foi necessário identificar os pontos fortes e fracos e o tipo de público de cada organização, além da questão das estratégias comunicacionais no ambiente digital.

\section{MATERIAIS E MÉTODOS}

A prática de extensão com entidades do Terceiro Setor ocorreu durante o ano letivo de 2017, por meio do projeto intitulado "Formação de Multiplicadores em Mídias Digitais para Organizações do Terceiro Setor". Para esta edição, foram selecionadas três organizações da cidade de Frederico Westphalen, as quais atuam nas áreas de educação, cultura, assistência social e agricultura familiar, a saber: a Central Única de Favelas (Cufa), a Associação de Pais e Amigos dos Excepcionais (Apae) e a Feira do Produtor. A Cufa atende pessoas em situação de vulnerabilidade social, não só em Frederico Westphalen, mas também em outros municípios da região, por meio de projetos em escolas e comunidades de bairros periféricos. Já a Apae presta serviços de educação para crianças e adultos com necessidades especiais. Por fim, a Feira do Produtor reúne mais de 20 feirantes e 11 agroindústrias ${ }^{1}$, ligados à Associação dos Feirantes de Frederico Westphalen, que busca valorizar o comércio de produtos da agricultura familiar.

Vale destacar que, apesar de o projeto ter relação com mídias digitais de uma forma mais ampla, nesta edição foi decidido focar apenas no Facebook, já que as organizações atendidas não dispunham de muito conhecimento técnico e nem de voluntários para cuidar de várias mídias ao mesmo tempo. O que ocorre é que as mesmas pessoas que estão envolvidas com a causa da entidade precisam atualizar as redes sociais digitais, o que acaba gerando uma sobrecarga. Tal questão foi percebida no diagnóstico, mais especificamente por meio da entrevista aberta (DUARTE; BARROS, 2009) aplicada com os gestores de cada entidade selecionada, a qual procurou saber aspectos referentes tanto ao capital humano existente quanto à comunicação digital que já era empreendida por cada uma das organizações.

1 Dados disponíveis em: http://www.barrilfm.com.br/galeria-fotos/1452/feira-do-produtor-de-fredericowestphalen. Acesso em: 13 mar. 2018. 
Prática extensionista no terceiro setor: capacitação para a comunicação na mídia social digital Facebook

Além disso, lançou-se mão da técnica de observação não-participante (GIL, 2002) com as fanpages da Apae e da Feira do Produtor, para auxiliar nesse processo de diagnóstico. No caso da Cufa, atendeu-se um público específico da entidade, constituído pelas Mulheres Empreendedoras, as quais ainda não possuíam fanpage do movimento. As Mulheres da Cufa realizam atividades de forma autônoma e empreendedora, como artesanato, corte e costura, estética e culinária.

Juntamente com o diagnóstico, começou a elaboração do conteúdo que serviu de base para todas as oficinas e que teve como temas-chave: redes sociais digitais; características e possibilidades do Facebook; definição de públicos e linguagem; periodicidade das publicações; definição de editorias; calendarização para postagens; uso de infográficos; check-ins e lives; fotografia; estratégia de presença digital e objetivos em estar no Facebook. Diante disso, procurouse trazer uma explicação para cada um dos assuntos citados, além de adaptá-los a cada organização, como por exemplo, definindo calendarização, públicos, editorias e objetivos para a Apae, Mulheres Empreendedoras e Feira do Produtor.

Elaborado o material específico de cada entidade, foi planejado como seriam as oficinas, tanto em relação ao conteúdo a ser ministrado quanto ao material didático de apoio. $\mathrm{Na}$ Apae, com a atividade realizada no dia 21 de setembro de 2017, foi possível abordar todos os temaschave anteriormente citados, porque as gestoras já tinham certa experiência e conhecimentos com o Facebook. Ainda assim, houve o cuidado de não utilizar termos muito acadêmicos nas falas, ou seja, dar preferência a uma linguagem mais simples e objetiva. Além disso, foram elaborados slides com tópicos e imagens, além de disponibilizá-los na forma impressa, para que as participantes pudessem fazer anotações sobre o que foi falado e tirar dúvidas posteriormente.

$\mathrm{Na}$ oficina com as Mulheres Empreendedoras da Cufa, realizada em 25 de novembro de 2017, também foram abordados todos os temas-chave, porém de uma forma muito mais simples e detalhada, já que elas não tinham nenhuma experiência com administração de fanpage, apenas utilizavam seus perfis pessoais às vezes. Ao final da oficina, foi criada a página das Mulheres Empreendedoras no Facebook, além de terem sido ensinadas algumas funções básicas, como convidar amigos para curtir, postar fotos, adicionar legendas e emojis.

Por fim, a oficina realizada com a Feira do Produtor no dia 01 de dezembro de 2017 também teve uma metodologia diferente das outras. Nesse caso, a criação da fanpage da entidade foi fruto de um projeto realizado anteriormente pelos estudantes da UFSM-FW, no segundo semestre letivo de 2016. Em 2017, novamente a Feira contou com estudantes da Universidade fazendo assessoria digital no segundo semestre letivo. Com isso, os produtores já possuíam uma noção de como administrar a página, mas acabavam fazendo mais postagens apenas nos meses 
Prática extensionista no terceiro setor: capacitação para a comunicação na mídia social digital Facebook

em que não estavam sendo assessorados. Por isso, nossa oficina foi no estilo tira-dúvidas, em que os participantes, equipados de seus smartphones, fizeram questionamentos sobre alguns aspectos do Facebook dos quais possuíam dúvidas, como programação de postagens, álbum de fotos, emojis, entre outros.

O fato é que em todos os casos, o planejamento do conteúdo a ser ministrado teve que ser um processo coletivo, já que havia a necessidade de entrar em contato com a realidade das pessoas atendidas, a fim de saber o grau de conhecimento que elas possuíam e suas principais necessidades. Só a partir disso foi possível planejar "o que" ministrar e "como" fazer com que o conteúdo fosse compreendido pelo público.

\section{RESULTADOS E ANÁLISES}

Ao final das atividades "Multiplicador3S", foram atendidas diretamente 14 pessoas e, indiretamente, cerca de 181 pessoas. O produto resultante do projeto de extensão é uma cartilha de presença e atuação nas mídias digitais ${ }^{2}$, produzida com base nos conteúdos ministrados nas oficinas, sempre atentando para a linguagem simples e explicação detalhada das funcionalidades das redes sociais digitais, em especial o Facebook.

Tomando por base o objetivo geral do projeto destaca-se que, em certa medida, ele foi cumprido. Isso porque os gestores e voluntários das organizações foram capacitados e acredita-se que a atuação das entidades no Facebook irá sim dar visibilidade à causa e captar doações e apoio. Entretanto, essa atuação, na maioria das vezes, não ocorrerá de forma tão planejada e estratégica, pois a oficina foi capaz de dar uma base de conhecimentos importantes, mas que ainda precisam ser desenvolvidos e aprimorados para ocorrerem da forma proposta no objetivo.

Acredita-se que a insuficiência do planejamento da comunicação em nível estratégico se deva a alguns fatores. Primeiramente, percebeu-se que nas entidades atendidas não há nenhum profissional formado atuando na área da comunicação para auxiliar nesse processo. O que ocorre é que as mesmas pessoas que estão envolvidas nas demais atividades da organização, também precisam gerenciar a área da comunicação e as mídias sociais digitais, o que, na maioria das vezes, sobrecarrega os responsáveis. Soma-se a isso, a falta de conhecimento dos indivíduos em utilizar as ferramentas digitais.

\footnotetext{
${ }^{2}$ Disponível em: https://issuu.com/kassialutz/docs/cartilha multiplicador3s 2018.
} 
Prática extensionista no terceiro setor: capacitação para a comunicação na mídia social digital Facebook

\section{CONSIDERAÇÕES FINAIS}

Um fato marcante no decorrer do projeto foi perceber que o conhecimento sobre as redes sociais digitais, que é considerado tão automático e natural, principalmente para as gerações mais jovens, é uma dificuldade para muitas pessoas. Isso pode ser ocasionado por diversos fatores, como baixa escolaridade, situação de vulnerabilidade social ou financeira, ou ainda, falta de interesse. Esses aspectos dificultaram algumas oficinas, pois o conteúdo teve de ser abordado de maneira muito simples e repetidamente, até que as pessoas entendessem. Outro fato marcante foi o interesse da maioria das pessoas em participar das oficinas, pois têm a consciência de que por meio do Facebook poderão atingir um público maior para apoiar suas causas.

Percebeu-se que o objetivo geral não foi totalmente atingido, pois a realidade das entidades atendidas ainda não possibilita que se pense na comunicação estratégica como foi idealizada no começo do projeto. Contudo, acredita-se que as atividades desenvolvidas foram uma importante base e um começo na "formação dos multiplicadores", já que auxiliou os voluntários a divulgar de forma mais eficiente as causas da organização e a se relacionar com os usuários na rede. Além disso, foi importante não só transmitir conhecimentos, mas também conhecer a Apae, as Mulheres Empreendedoras da Cufa e a Feira do Produtor, conversar com as pessoas, aprender com elas e entender a realidade em que estão inseridas. O conhecimento acabou se tornando uma construção coletiva, ou seja, uma das bases dos ideais de Freire (1979).

É claro que, considerando um ambiente ideal, um profissional de comunicação, especialmente um relações-públicas (RP), poderia potencializar de forma considerável a atuação das entidades do terceiro setor, não só no ambiente digital, como também por meio de outros processos comunicativos, pautados nos princípios das relações públicas comunitárias. O RP poderia, por exemplo, estabelecer parcerias com o poder público municipal e/ou empresas do segundo setor, desenvolver ações para sensibilizar a comunidade frederiquense no sentido de exercer sua cidadania, além de fortalecer a própria entidade internamente, por meio da transparência, diálogo e participação dos voluntários nas decisões. Enquanto isso não acontece, as pessoas envolvidas nessas organizações continuam a realizar um importante trabalho, lutando pela igualdade de direitos e por uma sociedade mais justa e inclusiva.

\section{AGRADECIMENTOS}

À Associação dos Pais e Amigos dos Exepcionais (Apae), Central Única de Favelas (Cufa) e Feira do Produtor, ambas da cidade de Frederico Westphalen, pela disponibilidade em participar das atividades desenvolvidas. 
Prática extensionista no terceiro setor: capacitação para a comunicação na mídia social digital Facebook

Aos voluntários que participaram do projeto: Marília Zabot e Tainara Schneider.

Ao projeto Fundo de Incentivo à Extensão (Fiex) que auxiliou no desenvolvimento das ações de extensão com aporte de recursos institucionais.

\section{REFERÊNCIAS}

DUARTE, Jorge; BARROS, Antonio. (orgs) Métodos e técnicas de pesquisa em comunicação. $2^{a}$ ed. São Paulo: Atlas, 2009.

FREIRE, Paulo. Pedagogia do oprimido. 7. ed. Rio de Janeiro: Paz e Terra, 1979.

GIL, Antônio Carlos. Como elaborar projetos de pesquisa. 4a ed. São Paulo: Atlas: 2002.

HJARVARD, S. Midiatização: conceituando a mudança social e cultural. Matrizes, v.8, n. 1, 2014. Disponível em: www.matrizes.usp.br. Acesso em: 19 abril 2016.

LIMA, Aline Fernanda. Relações Públicas nas entidades do terceiro setor: uma ação para construir cidadania. Janus, [s.1.], v. 1, n. 1, p. 93-103, ago. 2004. Disponível em: http://unifatea.edu.br/seer3/index.php/Janus/article/view/108. Acesso em: 14 mar. 2018.

PEREZ, R. A. Pensar la estrategia: otra perspectiva. 1. Ed. Buenos Aires: La Curija, 2012. Estrategias de comunicación. Barcelona: Ariel, 2001.

PERUZZO, Cicilia Maria Krohling. Relações Públicas no Terceiro Setor: tipologia da comunicação e conceitos de público. In: XXX Congresso Brasileiro de Ciências da Comunicação, 2007, Santos-SP. Anais... São Paulo: Intercom, 2007. Disponível em: http://www.intercom.org.br/papers/nacionais/2007/resumos/R1014-1.pdf. Acesso: 14 mar. 2018.

POLÍTICA Nacional de Extensão Universitária. Manaus: Forproex, 2012. Disponível em: http://www.utfpr.edu.br/estrutura-universitaria/pro-reitorias/prorec/diretoria-deextensao/documentos-da-extensao-de-ambito-nacional/politica-nacional-de-extensaouniversitaria-forproex-2012/view. Acesso em: 14 mar. 2018.

SILVA, Marcelo Pereira da; GUEDES, Ellida Neiva; SANTOS, Protázio César dos. Conscientização e participação: as relações públicas comunitárias na construção da cidadania. Organicom - Revista Brasileira de Comunicação Organizacional e Relações Públicas. São Paulo, n. 26, p. 87-98, jan/jul. 2017. Disponível em: http://www.revistaorganicom.org.br/sistema/index.php/organicom/issue/view/28/showToc. Acesso em 13 mar. 2017.

THOMPSON, J. B. A nova visibilidade. Matrizes, V.1, n. 2, 2008. Disponível em: http://www.matrizes.usp.br/index.php/matrizes/article/view/82. Acesso em: 13 nov 2014.

Recebido em: 28/07/2018

Aceito em: 05/04/2019 